\title{
THE SCIENTIFIC RESEARCH PROGRAMMES OF LAKATOS AND APPLICATIONS IN PARASITOLOGY
}

\author{
CABARET J.* \& DENEGRI G.**
}

\section{Summary:}

The methodology of scientific research programme (MSRP) proposed by Lakatos was in the line of the proposals made by Popper. MSRP were intended for constructing and evaluating research programme, which is unique among philosophers of science. Surprisingly, scientists dedicated to research in mathematics, physic or biology have not used much MRSP. This could be due to the fact that scientists are not aware of the existence of MSRP, or they find it difficult to apply to their own investigations. That is why we present firstly the main characteristics of this methodology (hard core - the group of hypothesis that are admitted by experts in the field, auxiliary hypotheses - which are intended to protect and refine the hypotheses of the hard-core, and heuristics for mending and evaluating the MSRP) and, secondly, propose an example in helminthology. We think that the methodology of Lakatos, is a useful tool, but it cannot encompass the large flexibility of investigations pathways.

KEY WORDS : Lakatos, philosophy of science, helminth, parasite, research programme.

S cientists are nowadays highly specialised and they hardly encompass the field of their own science. At the beginning of the $17^{\text {th }}$ century, it was assumed that scientific knowledge is produced by several individuals but it was possible for any individual to integrate all the existing knowledge, and in best cases, to increase it (Saint-Sernin, 2007). At the end of the $19^{\text {th }}$ century, the different parts of sciences were not any more integrated in a whole but disjointed into parallel knowledge (Saint-Sernin, 1995). We are also confronted with the alliance of science and technique. "The $20^{\text {th }}$ century has seen, if not the birth, at least the development of an alliance between science and technique which is called biotechnology. Technology is characterised by a contrast: highly accurate in its means and its results, and fuzzy on the future effects and sideeffects. Its nature is to be enthusiastic and blind. It is

* INRA, IASP, 213, Parasite Resistance and Virulence Team, 37380 Nouzilly, France.

** Laboratorio de Zoonosis Parasitarias, Departamento de Biologia, Facultad de Ciencias Exactas y Naturales, Universidad Nacional de Mar del Plata, CONICET, Funes 3250 (7600) Mar del Plata, Argentina.

Correspondence: Jacques Cabaret.

Fax : 33 (0)2 47427774 - E-mail: cabaret@tours.inra.fr fully movement, virtuosity, utility; technique ignores where it goes and what it does" (Saint-Sernin, 1995). Biohumanities is a view of the relationship between the humanities (especially philosophy and history of science), biology and society: it should overcome the limited alliance of technique and science. In this vision, the humanities not only comment on the significance or implications of biological knowledge, but add to our understanding of biology itself (Stoz \& Griffith, 2007). Philosophy of science may help to figure out the relationships between science, technique and societal demand, although it is not an evidence for everyone. "Physicist Richard Feymann is supposed to have said that philosophy of science is no more use to science than ornithology is to birds. In this paper we will try to show that this is very far from the truth. The complex and often troubled relations between science and society are critical to both parties, and the philosophy and history of science can belp to make this relationship work. They may be as valuable to science as conservation biology is to birds" (Stoz \& Griffith, 2007).

Philosophers of science are often very far away from the ordinary scientists. "The task of modern philosophy of science whose aim is the reconstruction of scientific methodology must be a comprehensive view of the scientific enterprise. It must take into consideration all factors that influence the acceptance or rejection of hypotheses and theories and must attempt to understand the mutual interaction of those factors" (Sattler, 1986). Systems models may apparently come closest to full representation of scientific methodology. Lazlo (1973) general systems model of the evolution of science could appear as easy of use for biologists. The systems model addresses to the crucial question of which factors determine retention or replacement of hypothesis. Lazlo (1973) founded value on a balance of empirical adequacy and integrative generality, although it is not easy to determine this balance. Scientists then rely on philosophers of science which are highly theoretical or systems' philosophers that appear as more in tune with reality, although their constructions are not really usable by scientists.

Lakatos (1978) developed a methodology of scientific research programmes and has then a unique position 
among philosophers in that respect. It remains that very few literature on the real use of the methodology of scientific research programmes is very limited as we found in the Web of Science database (from 1992 to 2007), either in biology, mathematics and physics or social sciences (less than 20 records). Lakatos has been the source of research programmes in folk psychology: "the Lakatosian model may seem promising - particularly to those who are interested in studying the development of children's understanding of the mind - the analogy between Lakatosian research programs and folk psychology cannot be made good because folk psychology does not possess anything analogous to the positive heuristic of a Lakatosian research program. I also argue that Lakatos' account of theories may not be the best one for developmental psychologists to adopt because of the emphasis which Lakatos places on the social embeddedness of scientific theorising" (Wringe, 2002). Metham (1993), a biologist, did view the development and the formulation of an apparently resilient theory of milk secretion (based on a key role of glucose on regulation) over the last 30 years as conform to the notion of progressive research programme and positive heuristic, as proposed by Lakatos.

The scientific research programmes have also been used in parasitology (Denegri, 1991, 1996, 1997; Denegri \& Cabaret, 2002). Our intention in this mini-review is to see how Lakatos programmes: i) are different from the Popper (and others) philosophical proposals in science; ii) help to construct a general framework for host-helminth parasite assemblages, and it will be taken as an example to clarify the methodology of scientific research programmes (MSRP).

\section{LAKATOS, POPPER AND FEYERABEND}

\section{THE DIFFERENT ATTITUDES TO RESEARCH AND SCIENCE}

T akatos (1922-1974) has played a special role in philosophy of science, due to his short life and $\checkmark$ background, and his close relationship with Popper, the dominant philosopher at the London School of Economics during the same period. Lakatos correspondence with Feyerabend (in Motterlini, 1999) shows that he has, with all his gravity, the secret of lightness. The philosophy of Lakatos has been developed pro and contra Popper. His PhD, "Essays on the logics of mathematical discovery" is a paraphrase of "The logic of scientific discovery of Popper" (1959), and it is in the pro phase. Much of the contra is in the "Popper on demarcation between science and pseudoscience, and induction" (Lakatos, 1974) edited by Schlipp. Although Lakatos stated that disagreement was not based on highly different opinions but rather on very small differences, which were enough not to see research programmes with the same eye. Differences are major in our opinion. Thus, the research programmes of Lakatos are a demonstration of the relative autonomy of theory in science, when the set of conjectures and refutations of Popper are not organised. Lakatos proposes a positive solution to induction, in order to escape from the provocative anarchism of Feyerabend. We have to be very careful, Lakatos did not intend to give researchers advices "My methodology deals with fully fledged research programmes, but has no intention to of handing out de vice to the scientist on how to arrive at good theories or on which of two rival theories he should work on" (in Motterlini, 1999).

According to Matheson (1996) "Lakatos's theory of rationality is based on the idea of the research programme, which is a sequence of theories characterized by $a$ hard-core (the features of the theories that are essential for membership in the research programme), the protective belt (the features that may be altered), the negative heuristic (an injunction not to change the hard core), and the positive heuristic (a plan for modifying the protective belt)".

"Usually we are faced with what I call a hard core of two, three, four, maximum five postulates. Consider Newton's theory: its hard core is made up of three laws of dynamics plus his law of gravitation... Instead of directing the modus tollens (e.g instead of A implies B, the contraposition is non-B implies non- $A$ ) of refutation to the hard core, one leads it against these auxiliary hypotheses, which in this sense, create a protective belt around the hard core" (Lakatos, 1973).

The protective belt is altered for two reasons. In its early stages, a research programme will make unrealistic assumptions (i.e. Newton's early assumption that the sun and the earth are point masses). The protective belt is altered in order to make the programme more realistic. It becomes testable only when it has achieved a sufficient degree of realism. Once the programme has reached the phase of testability, the protective belt is altered when the programme makes false experimental predictions. The alterations to the protective belt are not equal. Those alterations that allow the research program to make a novel prediction, then the alteration is said to be progressive. If the alteration is only an ad hoc manoeuvre, that is, it does not lead to any novel prediction, it is regarded as degenerate. Lakatos \& Zahar (1976) extended the definition of novel prediction to cover phenomena that may have been observed before the time of prediction but which were not among the problems which the alteration was designed to solve.

Lakatos (1978) indicates that a research programme is in 'good health' as long as a sufficient number of the alterations to it are progressive. "So I have replaced the descriptive unit in science. I shall not ask anymore whether a bypothesis is true or false anymore, or even whe- 
ther a problem shift is good or bad; what I shall ask is whether a research programme is progressive or degenerating". He explains how it is degenerating "It is degenerating if-during growth when we add layers of mathematical techniques to its protective belt - 1) it does not lead to stunning new predictions (at least occasionally, like Newton theory did over two and a half century); 2) all its bold predictions are falsified [proven to be inexact]; and 3) it does not grow in steps which follow the spirit of the programme". As stated by Matheson (1996), "Lakatos does not provide us with details concerning ways to measure degeneracy, nor does be locate the point at which degeneracy can prove fatal to a research programme". Matheson (1996) furthermore pointed that it remains difficult to compare one theory to another. "In particular be [Lakatos] would have to tell us what it is for one theory to have more observable content than another. If he presupposes some sort of cumulativity principle (i.e. that the better theory says everything true about observables that the worse one did plus a little bit more) than his theory is historically implausible. If he denies cumulativity, then the problem he faces, i.e. that of providing a sound basis for observational content, has foiled all who have tried to solve it".

Matheson (1996) asked much more than that was delivered by Lakatos: a methodology to evaluate the value of a research programme, its dynamics rather than to compare with other programmes. It is distinct from Popper's views since hypothesis can be falsified but the evaluation is not on hypotheses but on the whole programme, and its heuristic value. It is completely different from Feyerabend (1975) who was definitely against method.

\section{A GENERAL FRAMEWORK FOR HELMINTH RESEARCH IN HOST-PARASITE ASSEMBLAGE}

\section{FROM LIFE CYCLE TO ECOLOGY}

1 this framework has been presented in Denegri \& Cabaret (2002) and Denegri (2008). We present it here in a way that parasitologists could grasp better the concepts of hard core and auxiliary hypotheses.

- The hard core is: the knowledge of the alimentary chain of hosts explains and predicts their intestinal parasitic helminth fauna

This idea is present in Marcogliese \& Cone 1997. It has been also been reviewed extensively in fish parasites (Williams et al., 1992). Taking the example of Anoplocephlidae cestodes, the exclusive or partly herbivory of ruminants and equids explains that they harbour adult or larval stages of the worms. The hard core is a decision of a scientific community which is irrefutable.

There are many indications that the hard core is the rule. For example in the cestode family Anoplocephalidae (in Denegri, 2008), it is found that anoplocephalids are numerous and belong to many species in dedicated herbivores (sheep with Avitellina centripunctata, Helictometra giardia, Moniezia benedeni, Moniezia expansa, Stilesia hepatica, Stilesia globipunctata, Thysaniezia giardi, Thysaniezia ovilla, Thysanosoma actinoides) whereas in limited herbivores the number of species is limited (Bertiella mucronata, Bertiella studeri in human and non-human primates). A second example is presented by Denegri (1993) and is based on the trophic behaviour of oribatids mites which are intermediate hosts of Anoplocephalidae cestodes. According to the trophic classification of oribatid mites, the plant eater and the animal eater were the most infested. A third example concerns the Metastrongyloidea nematodes, for which gastropods are acting as intermediate hosts (Anderson, 2000). Three types of infection modes are found: i) in herbivores, with accidental ingestion of gastropods or larvae liberated onto the grass; $i$ i) in insectivores and rodents gastropods constitute an important part of the diet and infections are frequent; iii) among carnivores, a transport or paratenic host plays an important role.

- The protective belt (auxiliary hypotheses) is constituted of two groups of hypotheses, $i$ ) on life-cycle, and ii) on the development of helminth communities

The hypotheses on life cycle are constructed after Boskov (1986):

- All trematodes, cestodes and acanthocephalans are parasites; nematodes are either parasites or free living organisms.

- Trematodes, cestodes and acanthocephalans are hosted by animals, whereas nematodes can be hosted by plants or animals.

- All adult acanthocephalans are parasites of vertebrates, the majority of trematodes and cestodes are parasites of vertebrates but many adult nematodes are also parasites of invertebrates.

- Only several species of nematodes are parasite of invertebrate during larval life and free living when adults. - The development of secondary biological cycles is found in trematodes, cestodes and some nematodes parasite of vertebrates; these secondary life cycles are not present in acanthocephalans.

- The number of hosts is 2 to 4 in trematodes, 2 to 3 in cestodes, 2 in acanthocephalans, and 1 to 3 in nematodes parasites of vertebrates.

The hypotheses on communities are based mostly on Price (1987). Four models are presented, based on the concept of vacant niche and competition between species: 
- The non-asymptotic model: the species accumulate along time in the host, without any apparent saturation of the species community.

- The asymptotic equilibrium, based on the biogeography of islands (Mac Arthur \& Wilson, 1967), the equilibrium depending on colonization and extinction rates.

- The asymptotic equilibrium: it is a variant of the preceding model.

- The model of co-speciation (Brooks, 1979).

The auxiliary hypotheses can be modified without affecting hard core and the value of the research programme. Suppose that a trematode is found as a free-living organism. We will have only to modify the first hypothesis: "all trematodes are parasites" becomes "the vast majority of trematodes are parasites". It is not a negative heuristic (a reason to change the hard core). Conversely, a new fact such as a "a group of nematodes penetrate through the skin and infect hosts independently of their food habits" may induce to alter the hard core. The infection of Strongyloides is representative of such a situation in herbivores. It has been found in more frequently in small ruminants reared indoors (this the majority of records in temperate zones: see among others, Cabaret et al., 1986) but it can also be found in lambs grazed outdoors and gathered at night in places called "kraals" ("zriba" in Mauritania: Cabaret, 1976) in order to better control predation. In that case, food chain does not predict at all the prevalence of infection by Strongyloides. This nematode is a possible reason for modifying the hard core, and is that a negative heuristic. We could modify the auxiliary hypotheses so that this nematode is excluded from the general nematode group. We could propose the following modification in of the auxiliary hypotheses: nematodes having an extra-intestinal migration are not included. If we then think of nematodes harboured by wild rodents we will have quite a few species that migrates within hosts and are either orally transmitted or not. Then we should find some further hypothesis to protect the hard core. If these situations are frequent and finally constitute the main operations within the research programme, we should question how far we will go to protect the hard core. Positive heuristic is when we can predict a helminth fauna based on alimentary chain. Suppose we discover a new host, comparable to roe-deer in a temperate region. If we identify a helminth fauna similar to roe-deer in this new host, it is a positive heuristic. The importance of diet is demonstrated in Anisakids (Anderson, 2000). Anisakis simplex are parasites of pinnipeds and cetaceans, and larvae has been found free in the haemocel of euphasid shrimps, and the role of all eaters of shrimps remains in question (marine mammals can acquire larvae from eating infected fish, crustacean or squids). Thus the diet as a unique filter for parasites should be refined, possibly by enrichment of auxiliary hypotheses.

\section{DISCUSSION AND CONCLUSIONS}

P hilosophers of science are in an uneasy situation: science grows by "itself", and the role of philosophers is not always clear. Should they restrict their interest to the "passed" results of science? Or should they be more offensive and propose tracks for future avenues of science? The methodology of research programmes by Lakatos answers rather the second question, although it may prove useful to understand historical cases, as shown in Dicrocoelium dendriticum life-cycle elucidation (Denegri, 1997). The attitude of Lakatos in his methodology for scientific research programme is quite near to Louis Pasteur attitude (maintain as much as possible a hard core, without taking into account small deviations) rather than that of Claude Bernard (who was ready to investigate on deviations that could possibly modify the hard core of the theory) (C. Debru, 2007, ENS Paris, personal communication on Pasteur and Bernard research organisation). Lakatos attitude is thus one possibility for very efficient research (the Pasteur diverse and highly innovative researches). We should consider that it is not the only possibility for constructing research: the Bernard physiological findings are extremely important and were not acquired with a Lakatosian view of hard core, they are rather in agreement with Feyerabend absence of method (1999, in Motterlini): "Neither science nor the methodology of research programmes provide arguments against anarchism. Neither Lakatos nor anybody else has shown that science is better than witchcraft and that science proceeds in a rational way. Taste, not argument, guides our choice of science". Researchers might be puzzled by these two extreme considerations. We think that the methodology of scientific programmes is a really powerful tool for building a new research, evaluating its outcome (see Metham, 1993) but it is not the only way for successful research. The tool is fairly simple, it is a good way to start a research, and it is rarely used: we should promote this tool. We should also keep in mind that progress in science (and parasitology is no exception) is somewhat unpredictable. "Science, after all, is our creature, not our sovereign; ergo, it should be the slave of our whims, not the tyrant of our wishes" (Feyerabend, 1999 in Motterlini).

\section{ACKNOWLEDGEMENTS}

.C. is indebted to his institution (INRA) for providing access to a Master degree in Philosophy of Science (speciality: Logics, Philosophy, History and 
Sociology of Science) at The Sorbonne Paris 1, in order to enlarge his basic knowledge in Philosophy, which proved helpful when writing this review.

\section{REFERENCES}

ANDERSON R.C. Nematodes parasites of vertebrates. Their development and transmission. $2^{\text {nd }}$ Edition, CABI publishing, Oxon, 2000,UK, 650 p.

Boskov D. Conclusions from the comparasion of some of the major characteristics of trematodes, cestodes, acantocephalans and nematodes. Angew. Parasitol., 1986,27, 299307.

Brooks D. Testing the context and extend of host-parasite coevolution. Systematic Zoology, 1979, 28,299-307.

Cabaret J. Note sur le parasitisme dû aux nématodes et aux coccidies chez les animaux domestiques (bovins, moutons, chèvre, ânes) dans la région de Kaedi en Mauritanie. Revue d'Élevage et de Médecine Vétérinaire des Pays Tropicaux, 1976, 29, 221-226.

Cabaret J., Anjorand N. \& Leclerc C. Dairy goat farms in Touraine. I. Management, parasitism and estimation of disease in adult goats. Recueil de Médecine Vétérinaire, 1986, $162,575-585$.

Denegri G. Definición de un programa de investigación científica en parasitología: acerca de la biología de los cestodes de la familia Anoplocephalidae. Tesis de Licenciatura en Filosofía. Departamento de Filosofía. Universidad Nacional de La Plata, Argentina. 1991, 64 p.

Denegri G. Review of oribatid mites (Acarina) as intermediate hosts of tapeworms of the Anoplocephalidae family. Experimental and Applied Acarology, 1993, 17, 567-580.

Denegri G. La metodolología de los programas de investigación científica aplicada a la estructuración de un marco teórico-metodológico en parasitología. Revista de la Asociación de Ciencias Naturales del Litoral, 1996, 27, 69-77.

Denegri G. Contrastación de un programa de investigación científica en parasitología: reconstrucción de un caso histórico. Natura Neotropicalis, 1997, 28, 65-70.

Denegri G. Fundamentación epistomólogica de la parasitologia. Editorial de la Universidad Nacional de Mar del Plata (EUDEM)-Editorial Martin, Mar del Plata, Argentina, 2008, en prensa.

Denegri G. \& CABaret J. La metodología de los programas de investigación científica aplicada a la parasitología como un aporte epistemológico para la investigación experimental. Episteme, 2002, 14, 89-100.

FEYERABEND P. Against method: outline of an anarchist theory of knowledge. New left books, London, 1975.

LAKATOS I. Falsification and the Methodology of Scientific Research Programmes, in: Lakatos \& Musgrave (eds). Criticism and the Growth of Knowledge, Cambridge University Press, 1970.

Lakatos I. Popper on demarcation and induction, in: "The philosophy of Karl Popper". Schlipp P.A (ed.), Open court, La Salle, 1974, 241-273.
LAKatos I. The methodology of Scientific Research Programmes. Philosophical Papers Vol. 1. Cambridge University Press, 1978.

Lakatos I. \& Zahar E.G. Why Did Copernicus's Programme Supersede Ptolemy's? in: Westman R. (ed.). The Copernican Achievement, University of California Press, Los Angeles, 1976.

LAZLO E. A general systems model of the evolution of science. Scientia Milano, 1973, 107, 379-393.

MacArthur R. \& Wilson E. The theory of island biogeography. Princeton University Press, 1967, 69-93.

Marcogliese D. \& Cone D. Food weebs: a plea for parasites. Trend in Ecology Evolution, 1997, 12, 320-325.

MatHeson C. Historicist theories of rationality, 1996. Standford Encyclopedia of Philosophy. Consulted 23 ${ }^{\mathrm{d}}$ October 2007. http://plato.stanford.edu/entries/rationality-historicist/\#Lak

Meтнам T.B. The development of ideas on the role of glucose in regulating milk secretion. Australian Journal of Agricultural Research, 1993, 44, 509-522.

MotTerLini M. For and against method (Imre Lakatos and Paul Feyerabend). The University of Chicago Press, Chicago, 1999, $451 \mathrm{p}$.

POPPER K. The logic of scientific discovery. Huttchinson, London, 1959, 475 p.

Price P. Evolution in parasite communities. Int. J. Parasitol., 1987, 17, 209-214.

SAINT-SERnIN B. Le rationalisme qui vient. Gallimard, Paris, 2007, $327 \mathrm{p}$.

SAINT-SERnin B. La raison au XXème siècle. Seuil, Paris, 1995, $313 \mathrm{p}$.

SATTLER R. Biophilosophy. Analystic and holistic perspectives. Springer-Verlag, Berlin, 1986, 284 p.

STOTZ K. \& GRIFFITHS P.E. Biohumanities: Rethinking the relationship between biosciences, philosophy and history of science, and society. Quarterly Review of Biology, 2007, in press.

Williams H., Mackenzie K. \& MacCarthy A. Parasites as biological indicators of the population biology, migrations, diet, and phylogenetics of fish. Reviews in Fish Biology $\varepsilon$ Fisheries, 1992, 2, 144-176

WRINGE B. Is folk psychology a Lakatosian research program? Philosophical psychology, 2002, 15, 343-358. 